\title{
Heterotopic Cervical Pregnancy
}

Kh Zyiad*, Ahmad Kh, Hala $\mathrm{H}$ and Salem Kh

Razan Medical Center for Infertility, Arab Hospital, Nablus, Palestine

*Corresponding author: Kh Zyiad, Razan Medical Center for Infertility, Arab Hospital, Nablus, Palestine, Tel: +972598015124; E-mail: zyiad_abukhaizaran@yahoo.com

Rec date: March 03, 2016; Acc date: April 07, 2016; Pub date: April 12, 2016

Copyright: (c) 2016 Zyiad Kh, et al. This is an open-access article distributed under the terms of the Creative Commons Attribution License, which permits unrestricted use, distribution, and reproduction in any medium, provided the original author and source are credited.

\begin{abstract}
A 26 year- old lady who conceived by IVF-ICSI was diagnosed with heterotopic cervical pregnancy. She visited the emergency room with vaginal bleeding at 5 weeks +6 days gestational age and underwent careful intracervical gestatinal sac reduction with ring forceps under ultrasound guidance. The post operative course was uneventful and with a progressing healthy intrauterine pregnancy. We review the literature to suggest the best treatment for a successful pregnancy outcome.
\end{abstract}

Keywords: Heterotopic pregnancy; Cervical

\section{Introduction}

Heterotopic pregnancy is a rare event (I in 10,000-50,000) and the risk increased with assisted reproductive technology procedures (70fold increased risk) [1,2]. Heterotopic cervical pregnancy is even more unusual [3]. We present a rare case of heterotopic cervical pregnancy that was managed successfully with preserving the IUP. Up to the present, a total 37 cases of heterotopic cervical pregnancy have been reported in the English language literature.

The lady conceived by IVF-ICSI was diagnosed with heterotopic cervical pregnancy In her 1st pregnancy U/S. 2 days later She visited the emergency room with vaginal bleeding at 5 weeks +6 days gestational age, transvaginal U/S confirmed the diagnosis of heterotopic cervical pregnancy with both viable fetuses lady is hemodynamically stable with mild vaginal bleeding.

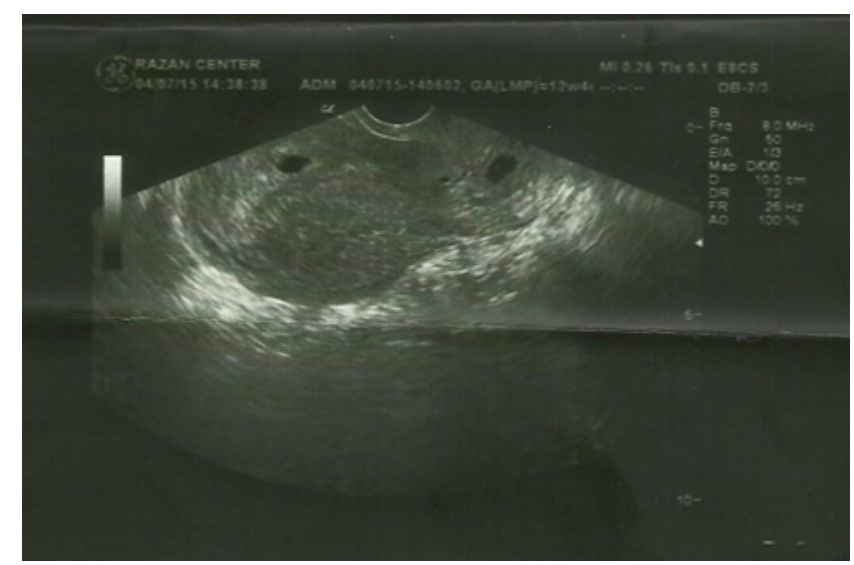

Figure 1: 1 st $\mathrm{u} / \mathrm{s}: \mathrm{u} / \mathrm{s}$ shows two gestational sacs. One intrauterine and the other is cervially located.

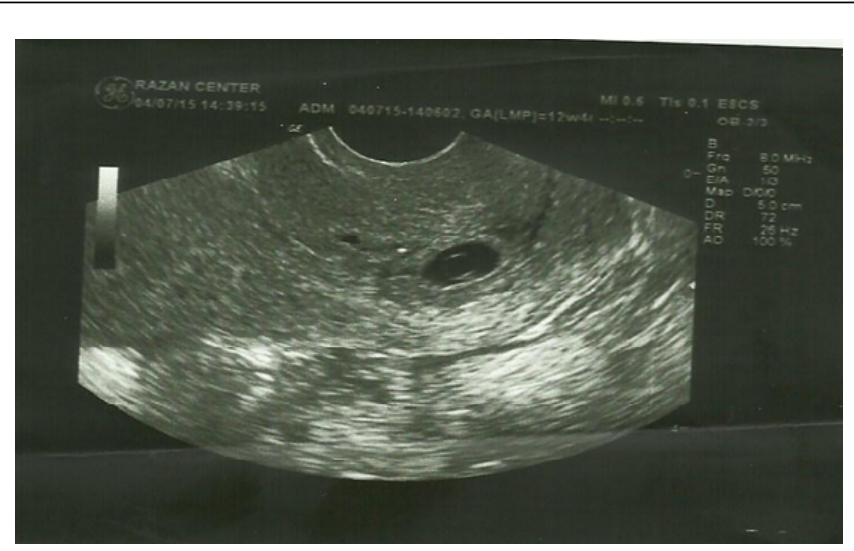

Figure 2: 2nd u/s showed amplified view for cervical gestational sac embedded in the endocervical canal.

\section{Material and Methods}

She was extensively counselled regarding her options of termination versus conservative management and opted for what was deemed the most intrauterine pregnancy-conserving approach. Figure 1, 1st $\mathrm{u} / \mathrm{s}$ : $\mathrm{u} / \mathrm{s}$ shows two gestational sacs, one intrauterine and the other is cervially located. Figure 2, 2nd u/s: showed amplified view for cervical gestational sac embedded in the endocervical canal.

Decision was made to use intraamniotic KCL injection and local Methotrixate into the ectopic component while preparing the lady in lithotomy position and inserting the speculum vaginally [4,5]. Partial expulsion of the cervical gestational sac was noticed. Complete cervical evacuation was done by ring forceps to avoid infection, bleeding and premature birth. Massive uterine bleeding did not occur [6]. The post operative course was uneventful. Microscopic findings demonstrated trophoblast and chorionic villi in the evacuated tissue [5,6]. Regular check-ups demonstrating the intrauterine pregnancy is progressing well. 
Citation: Zyiad Kh, Ahmad Kh, Hala H, Salem Kh (2016) Heterotopic Cervical Pregnancy. J Neonatal Biol 5: 215. doi:

Page 2 of 2

\section{Conclusion}

There is no universally accepted treatment modality for heterotopic cervical pregnancy mainly due to the limited number of cases in the literature. The management should be individualized based on the hemodynamic status of the patient, technical availability of the facility, and the skills of the surgeon.

\section{References}

1. Marcovici I, Rosenzweig BA, Brill AI, Khan M, Scommegna A (1994) Cervical pregnancy: case reports and a current literature review. Obstet Gynecol Surv 49: 49-54.

2. Ginsburg ES, Frates MC, Rein MS, Fox JH, Hornstein MD, et al. (1994) Early diagnosis and treatment of cervical pregnancy in an in vitro fertilization program. Fertil Steril 61: 966-969.
3. Raskin MM (1978) Diagnosis of cervical pregnancy by ultrasound: a case report. Am J Obstet Gynecol 130: 234-235.

4. Creinin MD, Feldstein VA (1995) Conservative management options for cervical pregnancy; case reports and literature review. Int J Fertil Menopausal Stud 40: 175-186.

5. Monteagudo A, Tarricone N, Timor-Tritsch I, Lerner J (1996) Successful transvaginal ultrasound-guided puncture and injection of a cervical pregnancy in a patient with simultaneous intrauterine pregnancy and a history of a previous cervical pregnancy. Ultrasound Obstet Gynecol 8: 381-386.

6. Frates MC, Benson CB, Doubilet PM, Di Salvo DN, Brown DL, et al. (1994) Cervical ectopic pregnancy: results of conservative treatment. Radiology 191: 773-775. 